\title{
A RARE PRESENTATION OF HYDATID CYST
}

Sukhamoy Barik ${ }^{1}$, Asok Kr Biswas², Goutam Giri ${ }^{3}$

\section{HOW TO CITE THIS ARTICLE:}

Sukhamoy Barik, Asok Kr Biswas, Goutam Giri. "A Rare Presentation of Hydatid cyst". Journal of Evolution of Medical and Dental Sciences 2014; Vol. 3, Issue 24, June 16; Page: 6683-6685,

DOI: $10.14260 /$ jemds/2014/2804

INTRODUCTION: Hydatid cyst caused by the larval stage of the parasite Echinococcus is manifested by slowly growing cystic mass. E. Granulosus accounts for the majority of the cases whilst E. Multilocularis and E. Vogeli are rare. Human happen to be accidental or incidental intermediate host and, as far as the parasite is concerned, a dead end. Liver is the most common organ involved and, together with the lung accounts for $90 \%$ of cases. The $10 \%$ cases that do not involve the liver and lung usually affect muscle, peritoneum, bone, spleen, pancreas, heart, kidney and brain instead. Here we describe a case of hydatid cyst of peritoneum.

CASE REPORT: A 40yrs old lady, hailing from middle class family, from canning 24PGS (S), was admitted in hospital (RKMSP) with pain in right lower abdomen for last 2yrs. It was progressive, intermittent and dull in nature, increasing during menstrual periods. There was also menorragia for last 6-7months. There was no significant past history. On per abdominal examination a soft mass $\left(6 \times 6 \mathrm{~cm}^{2}\right)$ palpated in right lower abdomen, of $20 \mathrm{wks}$ size. On bimanual examination a mass similar size, felt through the right fornix, which was separated from uterus. Complete blood cell count, electrolytes, eosinophil count, serum biochemistry and urinalysis were within normal limits.

Chest X-ray was normal. Ultra sonogram showed bulky uterus with subserous fibroid near fundus $\left(11 \mathrm{X} 9 \mathrm{~cm}^{2}\right)$. She was planned for abdominal hysterectomy. During operation a mass was seen, which was attached to the parietal peritoneum below umbilicus of right side of anterior abdominal wall. The mass contained multiple cysts, greyish-white in color, variable sizes, without any fluid or solid component (fig. 1).

Cysts wall were of variable thickness with mucoid glistening surface. No ascites was detected. Specimen was sent for histo pathological examination. Liver, gall bladder were normal. Uterus, tubes and ovaries were normal. Cystic mass was removed followed by total abdominal hysterectomy with bilateral salpingo-oophorectomy was done. Histopathology of cystic mass showed laminated eosinophilic chitin layer of parasite.

Adhered fibrocollagenous stroma showed chronic inflammation with palisading of epitheloid histocytes and foreign body giant cell reaction-a case of hydatid cyst of peritoneum (Fig. 2). No evidence of malignancy. Post- operative period was uneventful. Patient was discharged on $7^{\text {th }}$ postoperative day with usual advices along with Tab albendazole (400mg) once daily for 2 months for hydatid cyst. 


\section{CASE REPORT}

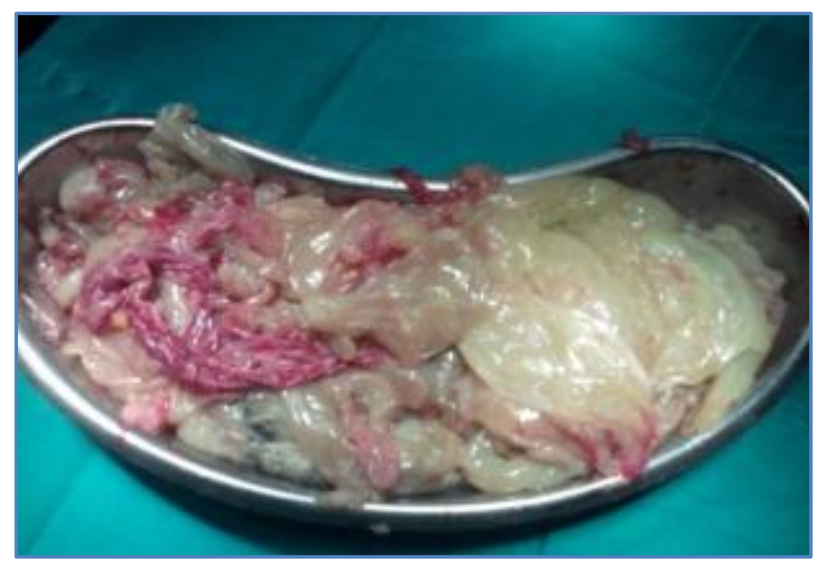

Fig. 1: Multiple greyish-white cystic mass
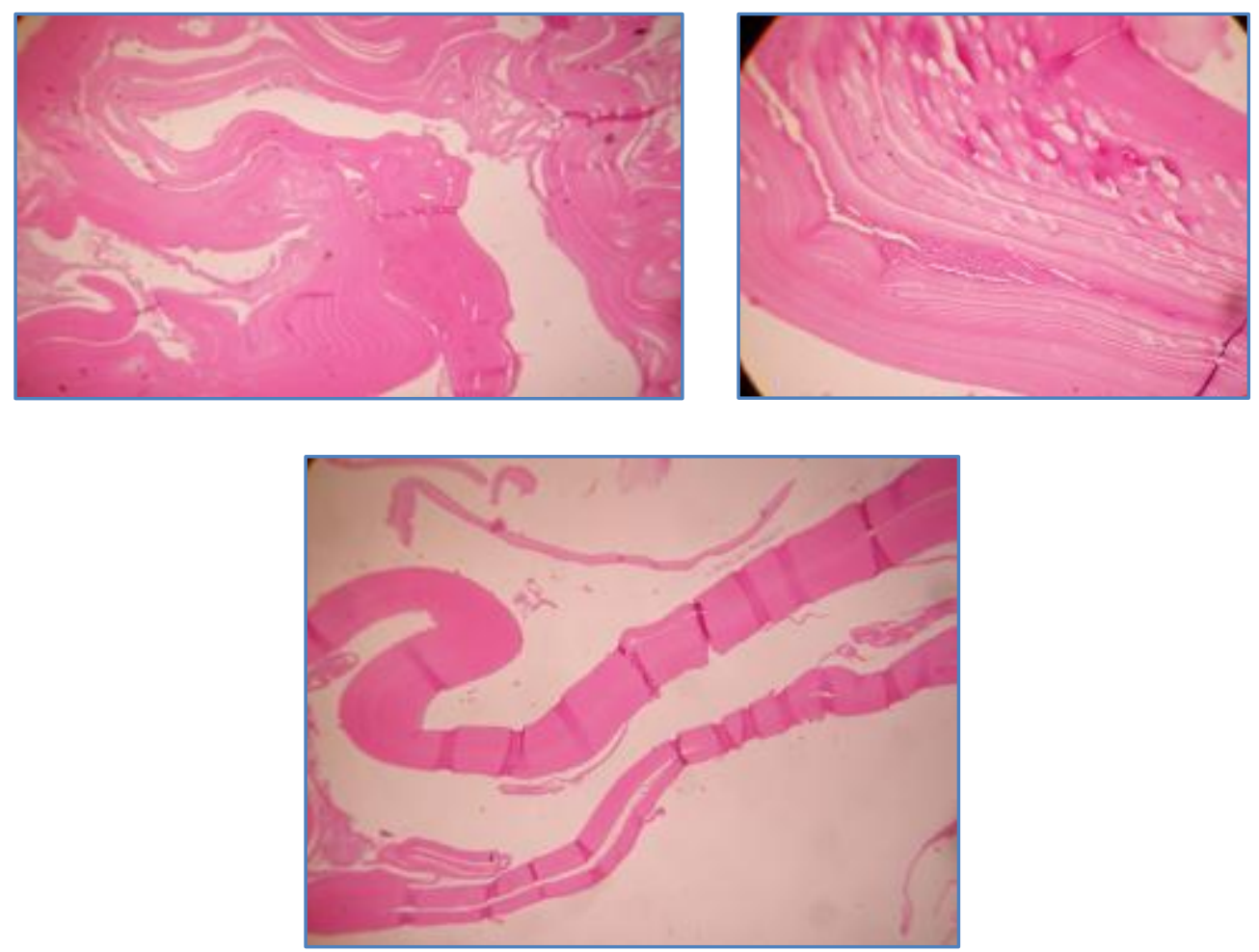

Fig. 2: HPE of cystic mass showing hydatid cyst

DISCUSSION: The adult worm resides in the intestine of its definitive host, the dog and related carnivores. The eggs passed in the feces are ingested by grazing sheep, goats and cattle. The eggs hatch, penetrate the host's intestinal wall and reach the liver through the portal vein. From there they are distributed by the bloodstream to the lungs and other organ systems.

Eggs gets transformed to the larval stage, the scolex, which can continue to multiply asexually indefinitely within the hydatid cyst. The natural cycle is completed when a hydatid cyst is devoured by a canine host. The multiplication of the larval scolices results in a slow but steady physical enlargement of the cystic colony. Since the enlargement is very gradual the patient's symptoms are 
rarely acute. The cyst consists of three layers. The outer most, or the pericyst, is an adventitial layer of host origin. The middle layer is the outer chitinous covering of the parasite or the laminated membrane. The innermost germinal layer gives rise to the scolices. ${ }^{2}$

The usual mode of acquiring the infection is through ingestion of contaminated vegetables. Symptoms are caused by pressure effects but are vague initially. Pain, cough, low-grade fever, and the sensation of abdominal fullness are common features. As the cyst grows, the symptoms become more specific depending on the specific structures involved. Secondary complications include of infection or rupture of the cyst. ${ }^{3}$

Theoretically no organ is immune form hydatid disease. When the relatively rare sites are involved, the mainstay of diagnosis remains a high index of suspicion supplemented by radiologic and hydatid serology 4 . Although eosinophilia is expected in patients with parasitic infestations, it has been reported to be present in only $25 \%$ of cases of hydatid disease. ${ }^{1}$

Sonography and CT are useful for delineating the location of cyst, but the findings are nonspecific. Surgical removal remains the main form of definitive treatment. Chemotherapy is indicated in inoperable cases because of location, multiplicity of organ involvement or in patients with serious medical conditions ${ }^{1}$.

\section{REFERENCES:}

1. Dandan IS, Soweid AM, Abaid F. Hydatid Cysts. eMedicine [Online] http://www.emedicine.com/med/topic1046.htm].

2. Saidi F. In: Mastery of Surgery. 2. Nyhus LM, Baker RJ, Sadisten DC, editor. London, Little, Brown, and Company; 1992. Treatment of echinococcal cysts; pp. 818-37.

3. Smego RA, Smego DR. Management of Human Echinoccosis: Review of Surgical and Medical Approaches. Pakistan Journal of Surgery. 1987; 3: 29-34.

4. Husen YA, Nadeem N, Aslam F, Bhaila I. Primary splenic hydatid cyst: a case report with characteristic imaging appearance. J Pak Med Assoc. 2005; 5: 219-21. [PubMed].

\section{AUTHORS:}

1. Sukhamoy Barik

2. Asok Kr Biswas

3. Goutam Giri

\section{PARTICULARS OF CONTRIBUTORS:}

1. Senior Resident, Department of Obstetrics and Gynaecology, Ramakrishna Mission Seva Pratishthan.

2. Associate Professor, Department of Obstetrics and Gynaecology, Ramakrishna Mission Seva Pratishthan.

3. Assistant Professor, Department of Obstetrics and Gynaecology, Ramakrishna Mission Seva Pratishthan.

\author{
NAME ADDRESS EMAIL ID OF THE \\ CORRESPONDING AUTHOR: \\ Sukhamoy Barik, \\ RKMSP, 99, Sarat Bose Road, \\ Kolkata-700026, \\ West Bengal. \\ Email: sukhamoy83@gmail.com
}

Date of Submission: 24/05/2014. Date of Peer Review: 25/05/2014. Date of Acceptance: 03/06/2014. Date of Publishing: 13/06/2014. 